\title{
Less attentional selectivity as a result of declining inhibition in older adults
}

\author{
STEVEN P. TIPPER \\ McMaster University, Hamilton, Ontario, Canada
}

\begin{abstract}
It has been hypothesized that a salient feature of the aging process is a decline in the ability to inhibit intrusive irrelevant information. Examination of distractor interference and negative priming effects in a group of older adults confirmed this hypothesis: Distracting information interfered with performance more in older subjects, and this population produced less evidence for inhibitory mechanisms when compared with younger adults. It is suggested that inhibition may be a general mechanism that is particularly vulnerable in a variety of clinical populations, and it may provide a marker for early detection of syndromes characterized by breakdown in cognitive processes.
\end{abstract}

Selectivity in perception and action is crucial for successful goal-directed behavior. Complex environments containing numerous objects that afford an enormous range of actions are ubiquitous. Therefore, the inhibiting of inappropriate thoughts and actions is an extremely important mechanism.

Recent research has revealed individual differences in the ability to inhibit the processing of to-be-ignored objects during selective attention tasks (Tipper \& Baylis, 1987). Reduced inhibitory mechanisms are particularly salient in clinical populations. In both schizophrenics (Beech, Powell, McWilliams, \& Claridge, 1989) and children with attentional deficit disorder (ADD; McLaren, 1989; Tannock, Schachar, Carr, Chajczyk, \& Logan, 1989), the ability to inhibit distracting information in a selective attention task is impaired. The observation of reduced inhibition in these populations supports previous findings of increased interference from distractors during selection and response to target stimuli.

Similar increased distractor interference during selective attention tasks has also been reported in older adults (Comalli, Wapner, \& Werner, 1962; Madden, 1983). Such observations in attention, and other tasks such as free recall from memory (Fuld, Katzman, Davies, \& Terry, 1982), have led to the hypothesis that older adults are also less able to inhibit intrusive external stimuli and internal thoughts (Hasher \& Zacks, 1988).

The following experiment was carried out to examine the hypothesis that inhibition declines with age. Two effects are examined to infer the relative level of distractor intrusion and inhibition: Interference effects measure the ability to ignore irrelevant stimuli during responding to a prespecified target. Negative priming measures the

This research was supported by an NSERC (CANADA) grant. The assistance of Susan Anderson and Jamie Brehaut is gratefully acknowledged. Correspondence may be addressed to Steve Tipper, Psychology Department, McMaster University, Hamilton, Ontario L8S 4K1, Canada. amount of inhibition associated with the distractor during selection of the target. Negative priming is based on the following logic: If the internal representations of a distractor are associated with inhibition during selection of the target, then processing of a subsequent stimulus requiring the inhibited representations should be impaired. For example, if a to-be-ignored picture of a dog is associated with inhibition, then response to a subsequent picture of dog, assumed to require the same or similar internal representations, should be impaired. Such observations of negative priming have been made in a variety of situations (Neill, 1977; Tipper, 1985).

Therefore, the following pattern of results is to be predicted: First, in support of previous research, distracting information should interfere with selection and response to target stimuli more in old than in young adults. Second, in line with the reduced-inhibition hypothesis, greater interference effects should be accompanied by reduced negative priming effects.

\section{METHOD}

\section{Subjects}

Twenty older subjects were recruited from the local community. Their mean age was 66 years (range, 57-77). For comparison, data from an undergraduate population with a mean age of 21 years (range, 17-25) previously reported by Tipper, Bourque, Anderson, and Brehaut (1989) were also included in the data analysis to provide a contrast between the developmental stages. ${ }^{1}$

\section{Design}

A $2 \times 3$ mixed design was employed in this experiment. The betweensubjects factor was subject group (younger vs. older adults). The withinsubjects factor of condition consisted of three levels: neutral, control, and ignored repetition. The details of these conditions follow.

A trial consisted of a prime followed by a probe display. Each display consisted of two simple line drawings out of a possible six. One picture, to which the subject's attention was to be directed, was at fixation, and to the left or the right of it was the other to-be-ignored picture. In the control condition (C), the pictures in the prime and probe display were completely unrelated. The neutral condition $(\mathrm{N})$ consisted of a similar prime display, whereas in the probe display, the ignored distractor was a meaningless stimulus corresponding to one of the six 


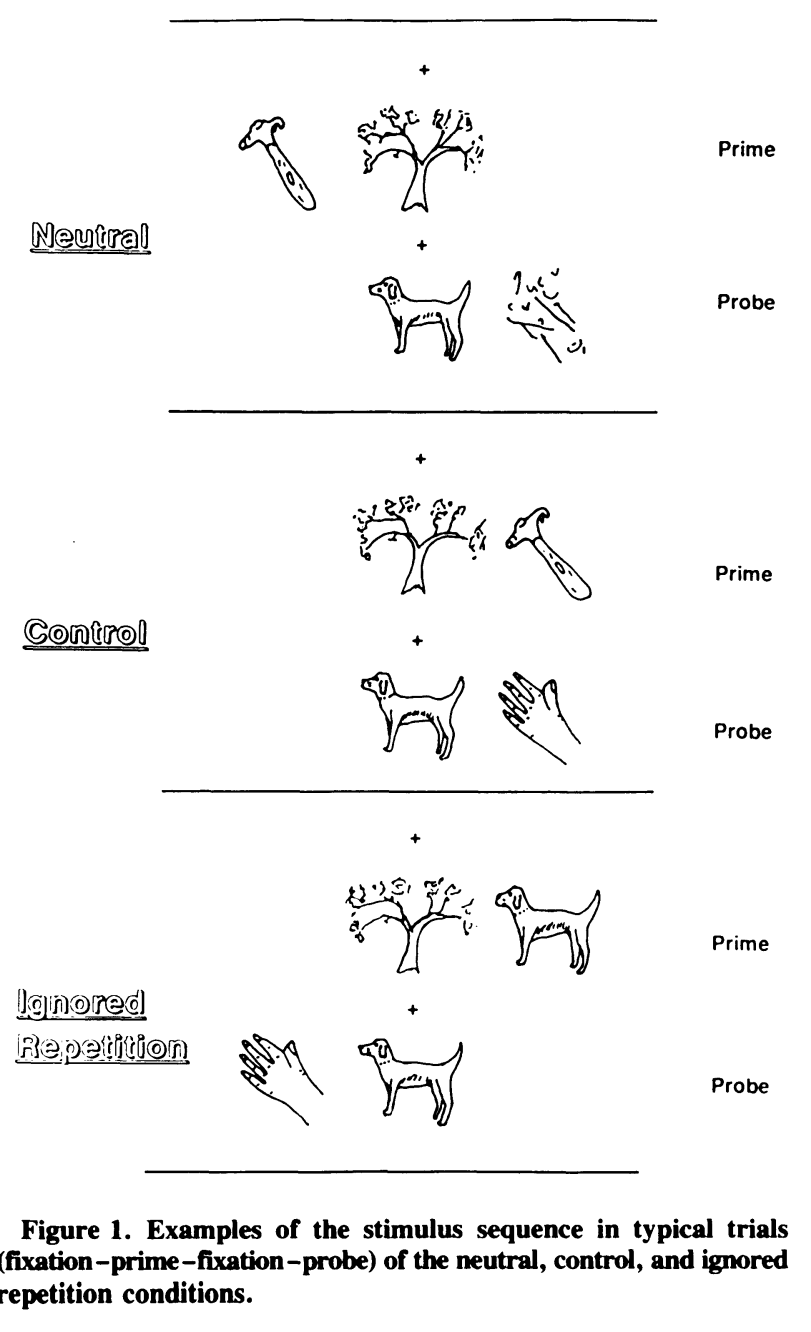

target stimuli in terms of features. In the ignored repetition condition (IR), the ignored distractor on the prime display was the same as the stimulus to be attended on the probe display. (See Figure 1.)

A measure of interference was obtained by comparing the neutral and control conditions. Previous work has shown that a distractor stimulus that is from the same stimulus set as the target can impair response. This observation has led to the conclusion that the distractor is analyzed to the level of identification in parallel and competes with the target for response (Stroop, 1935; Eriksen \& Eriksen, 1974; Schaffer \& LaBerge, 1979; Underwood, 1977). Therefore, if the distractor is competing with the target beyond the feature level, reaction time (RT) in the control condition should be larger than in the neutral condition. A measure of negative priming was obtained by contrasting control, where there is no relationship between the prime distractor and subsequent probe, with ignored repetition, where the ignored prime is identical to the subsequent probe. Inhibition will be reflected by longer RTs in the ignored repetition condition.

\section{Apparatus and Stimuli}

Stimuli for this experiment consisted of six simple line drawings of a dog, table, tree, hammer, hand, and wheel, as well as six meaningless (neutral) stimuli. The neutral stimuli corresponded to each of the meaningful pictures, in that they contained the same features but in an exploded form, whereby the features were not conjoined to form a unified object. The pictures were drawn in black and mounted on white tachistoscope cards. The stimuli subtended angles of between $1.25^{\circ}$ and $2.87^{\circ}$ horizontally and between $1.65^{\circ}$ and $2.13^{\circ}$ vertically, while the visual angle from fixation to the center of the distractor was $2.58^{\circ}$. Trials were presented using a Gerbrands three-field tachistoscope, with RTs and errors being recorded automatically by an Apple Ile computer. There were 12 practice trials and 30 trials per condition (see Tipper et al., 1989 for further details). Only RTs for correct trials were analyzed.

\section{Procedure}

The procedure was the same as that employed by Tipper et al. (1989). The subjects were tested in a dimly lit room in one 20 -min session. They were told that they would be required to name pictures presented in the tachistoscope, and were shown the six pictures with their appropriate names. The experimenter explained that the following events would be presented: First, a fixation cross appeared, on which attention was to be focused. Second, a display of two pictures appeared briefly. The subjects were told to attend to the central stimulus where the fixation cross had been, and to ignore the one to the side (either left or right). They were asked to remember this attended stimulus, but not to respond to it immediately. The fixation cross then reappeared, followed by the probe display. The subjects were requested to respond vocally by naming the central stimulus in the probe display as quickly as they could while avoiding making too many errors. It was emphasized that they should ignore the stimulus to the side, since it was only placed there to distract them. After responding quickly to the attended probe stimulus, the subjects were then asked to recall the attended prime stimulus, in order to ensure that the attended drawing was selected from the prime display. These responses were noted by the experimenter. Errors on either the prime or the probe display resulted in that trial's RT not being included in the median RTs. Five blocks of trials containing 12, 22, 25, 23, and 24 trials were presented, and the subjects were provided with a short (approximately 1-min) break after each block. The approximate intertrial interval was $3 \mathrm{sec}$.

Thus, the presentation of stimuli throughout the experiment ran as follows: (1) The experimenter said "go" and started the trial; (2) the fixation cross appeared for $1,000 \mathrm{msec}$; (3) the prime was displayed for $100 \mathrm{msec}$; (4) the fixation cross was displayed for $1,000 \mathrm{msec}$; (5) the probe display appeared for $100 \mathrm{msec}$; (6) the subject made a speeded response to the attended stimulus in the probe display, followed by recall of the attended stimulus in the prime display; and (7) there was an intertrial interval.

\section{RESULTS AND DISCUSSION}

Means of median RTs and mean errors are reported in Table 1. These RT data were analyzed in a two-way mixed analysis of variance. The between-subjects factor of age was highly significant $[F(1,38)=27.391, p<$ $.0001]$, replicating the well-established finding that older subjects' RTs are slower than those of young adults. The within-subjects factor of condition (N, C, and IR) was also significant $[F(2,76)=7.341, p<.002]$, as was the interaction between subject group and condition $[F(2,76)=$ $5.289, p<.01]$.

Further analysis (Wilcoxon test) revealed that older subjects produced a significant distractor interference effect $(p<.01)$ and significant positive priming $(p<.05)$,

Table 1

Mean of Median Reaction Times and Percent Errors for Younger and Older Adults

\begin{tabular}{|c|c|c|c|c|c|c|}
\hline & \multicolumn{2}{|c|}{ Neutral } & \multicolumn{2}{|c|}{ Control } & \multicolumn{2}{|c|}{$\begin{array}{c}\text { Ignored } \\
\text { Repetition }\end{array}$} \\
\hline & $M$ & $\%$ Error & $M$ & $\%$ Error & $M$ & \% Error \\
\hline Young adults* & 561 & 6.2 & 569 & 5.2 & 584 & 6.7 \\
\hline Older adults & 758 & 7.3 & 800 & 10.3 & 774 & 12.3 \\
\hline
\end{tabular}

* Data previously reported in Tipper et al. (1989). 
whereas young adults produced no distractor interference and significant negative priming $(p<.02)$.

Analysis of errors revealed a marginal effect of age $[F(1,38)=3.155, p<.08]$, supporting the RT data, a main effect of condition $[F(2,76)=4.945, p<.01]$, and an interaction between age and condition $[F(2,76)=$ $3.895, p<.03$ ]

Further Wilcoxon analysis revealed no significant contrasts in the young adults; a significant interference effect $(p<.02, \mathrm{~N}<\mathrm{C}$ ) in the older adults, supporting the RT data; and significantly more errors in IR than in $\mathrm{C}(p<.02)$. The latter result suggests that older subjects produce a speed-accuracy tradeoff: Relative to the control condition, RTs were faster for responses to a stimulus just ignored, but errors were greater.

Such a pattern of results is what would be predicted from a model proposing reduced inhibition in older subjects. Distracting pictures intrude into the processing of target stimuli by older adults more than is the case in young adults, and older adults show less evidence for negative priming. Indeed, these older subjects produced positive priming, where the ignored stimulus speeded responses to subsequent probes, but they also produced more errors. Thus, an interpretation of such observations is that the internal representations of the distractor picture were still active when the probe was presented. Consequently, there was a speeding of responses and greater confusion (hence greater errors), indicating a failure to inhibit this irrelevant information.

It would appear, therefore, that inhibition is a particularly vulnerable mechanism. As has been discussed, it is weaker in schizophrenics, ADD children, and older people. However, the apparent generality of reduced inhibition has to be contrasted with the task-specific nature of obtained results. Even though reduced negative priming in older subjects has also been observed in letter naming (Hasher, Stoltzfus, Zacks, \& Rympa, in press; McDowd \& Oseas, in press) and in localization tasks (McLaren \& Tipper, unpublished), it is not observed in Stroop (1935) color-naming tasks (Tipper, unpublished; McLaren, unpublished). However, as noted previously (Tipper et al., 1989), Stroop tasks (where the to-be-attended and ignored stimuli are dimensions within an object) may not be representative of typical perceptuomotor interactions with the environment, and therefore atypical results may be accounted for by a lack of ecological validity (see Tipper \& McLaren, 1990, for further discussions).

Further studies of populations demonstrating reduced selectivity (e.g., Alzheimer's patients: Freed, Corkin, Growdon, \& Nissen, 1988) are therefore needed, to confirm the hypothesis that inhibition is vulnerable to breakdown. The examination of inhibition may provide a useful marker for early identification of syndromes characterized by impaired cognitive processes.

\section{REFERENCES}

Beech, A. R., Powell, T. J., McWilliams, J., Claridge, G. (1989). Evidence of reduced "cognitive inhibition" in schizophrenia. British Journal of Psychology, 28, 110-116.

Comalli, P. E., Wapner, S., \& Werner, H. (1962). Interference effects of a Stroop color-word test in children, adulthood, and aging. Journal of Genetic Psychology, 100, 47-53.

ERIKSEN, B. A., ERIKSEN, C. W. (1974). Effects of noise letters upon the identification of a target letter in a nonsearch task. Perception \& Psychophysics, 16, 143-149.

Freed, D. M., Corkin, S., Growdon, J. H., \& Nissen, M. J. (1988). Selective attention in Alzheimer's disease: CSF correlates of behavioural impairments. Neuropsychologia, 26, 895-902.

Fuld, P. A., Katzman, R., Davies, P., \& Terry, R. D. (1982). Intrusions as a sign of Alzheimer's dementia: Chemical and pathological verification. Annals of Neurology, 11, 155-159.

Hasher, L., Stoltzfus, E. R., Zacks, R., \& Rympa, B. (in press). Aging and inhibition. Journal of Experimental Psychology: Learning, Memory, \& Cognition.

HASHER, L., \& ZACKS, R. (1988). Working memory, comprehension, and aging: A review and a new view. In G. K. Bower (Ed.), The psychology of learning and motivation (Vol. 22, pp. 193-225). New York: Academic Press.

MADDEN, D. J. (1983). Aging and distraction by highly familiar stimuli during visual search. Developmental Psychology, 19, 499-507.

MCDOWD, J. M., \& OsEAS, D. M. (in press). Aging, inhibitory processes, and negative priming. Journal of Gerontology.

MCLAREN, J. (1989). The development of selective and sustained attention in normal and attentionally disordered children. Unpublished doctoral dissertation, Dalhousie University, Halifax, Nova Scotia.

NeILL, W. T. (1977). Inhibition and facilitation processes in selective attention. Journal of Experimental Psychology: Human Perception \& Performance, 3, 444-450.

SCHAFFER, W. D., \& LABERGE, D. (1979). Automatic semantic processing of unattended words. Journal of Verbal Learning \& Verbal Behavior, 18, 413-426.

Stroop, J. R. (1935). Studies of interference in serial verbal reactions. Journal of Experimental Psychology, 18, 643-662.

Tannock, R., Schachar, R. J., CarR, R. P., Chasczyk, D., \& LOGAN, G. D. (1989). Effects of methylphenidate on inhibitory control in hyperactive children. Journal of Abnormal Child Psychology, 17, 473-491.

TIPPER, S. P. (1985). The negative priming effect: Inhibitory effects of ignored primes. Quarterly Journal of Experimental Psychology, 37A, 571-590.

TIPPER, S. P., \& BAYLIS, G. C. (1987). Individual differences in selective attention: The relation of priming and interference to cognitive failure. Personality \& Individual Differences, 8, 667-675.

Tipper, S. P., Bourque, T., Anderson, S., \& Brehaut, J. (1989). Mechanisms of attention: A developmental study. Journal of Experimental Child Psychology, 48, 353-378.

TIPPER, S. P., \& MCLAREN, J. (1990). Evidence for efficient visual selectivity in children. In J. T. Enns (Ed.), Advances in psychology. The development of selective attention: Research and theory. New York: Elsevier North-Holland.

UNDERWOOD, G. (1977). Attention, awareness and hemispheric differences in word recognition. Neuropsychologia, 15, 61-67.

\section{NOTE}

1. Both groups of subjects were tested at approximately the same time (summer, 1987). Since then, however, I have moved to a new University and no longer have access to the same equipment. Therefore it was not possible to test a new undergraduate control group. 